
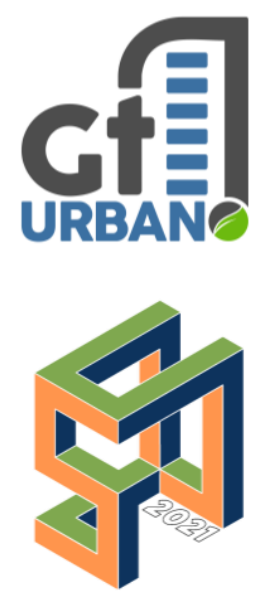

SINGEURB

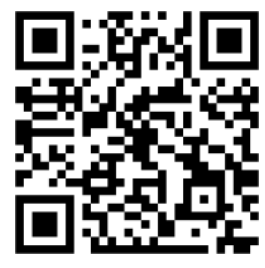

Como citar:

PAES, Carolina

Folena Cardoso;

SANTOS, Vitória

Alves dos. Terminais periféricos do Eixo Anhanguera (Goiânia - GO): vitalidade à luz da forma e atividades. In: III SIMPÓSIO

NACIONAL DE GESTÃO E ENGENHARIA URBANA: SINGEURB, 2021, Maceió. Anais... Porto Alegre: ANTAC, 2021. p. 300307.

Disponível em: https://eventos.antac. org.br/index.php/sin geurb/issue/view/14

\title{
Terminais periféricos do Eixo Anhanguera (Goiânia - GO): vitalidade à luz da forma e atividades urbanas
}

\author{
Peripheral terminals of Anhanguera axi \\ (Goiânia-GO): vitality in the light of form and
} urban activities

Carina Folena Cardoso Paes, Universidade Federal de Goiás (UFG), carinafolena@ufg

Vitória Alves dos Santos, Universidade Federal de Goiás (UFG), vitoria-alves-santos@hotmail.com

\section{RESUMO}

Este trabalho focaliza a importância de se estimular o desenvolvimento de centralidades em zonas intersticiais, entre o centro e as periferias urbanas, como forma de atenuar a pegada ecológica dos bairros periféricos pela redução dos deslocamentos. Nessa lógica, o objetivo deste trabalho é avaliar se os entornos dos terminais periféricos do Eixo Anhanguera, em Goiânia, desempenham o papel de centralidades urbanas no atendimento às necessidades cotidianas dos usuários de suas linhas alimentadoras. Trata-se de uma pesquisa desenvolvida no âmbito da iniciação científica e que traz resultados parciais acerca do objeto em análise. Os procedimentos metodológicos compreendem o estudo do uso do solo e a aplicação de indicadores de grau de interação de atividades urbanas como recursos para avaliar a vitalidade dos entornos dos terminais, com vistas a concluir se desempenham ou não a função de centralidades. Os resultados demonstram as fragilidades que impactam na não efetivação de centralidades nos entornos dos terminais, destacando-se a escala de ocupação das arquiteturas e a pouca diversificação dos usos. Sendo assim, o estudo evidencia a projeção que as atividades e formas urbanas detêm na consecução de um projeto de cidade sustentável e voltada às pessoas.

Palavras-chave: Cidade policêntrica, Desenho urbano, Deslocamentos sustentáveis.

\begin{abstract}
This work focuses on the importance of stimulating the development of centralities in interstitial zones, which are placed between the center and the urban peripheries, as a way to attenuate the ecological footprint of peripheral neighborhoods by reducing displacements. In this logic, this work aims to evaluate whether the peripheral terminals surroundings of Anhanguera Axis, in Goiânia, configure urban centralities in meeting daily needs of their feeder lines users. This research belongs to a scope of scientific initiation and brings partial results about the object under analysis. The methodological procedures include the study of land use and the application of indicators related to the degree of urban activities interaction in order to assess the vitality of terminals surroundings as to conclude whether, or not, do
\end{abstract}


they configure urban centralities. The results shows the weaknesses that impact on the noneffectiveness of centralities in terminals surrounding areas, about which we highlight the occupation scale of the architectures and the incipient diversification of activities. Thus, this study presents the projection that both urban forms and activities have in achieve a sustainable city project aiming at people.

Keywords: Policentric city, Urban design, Sustainable displacements.

\section{INTRODUÇÃO}

Os interstícios urbanos são espaços estratégicos à ampliação da qualificação da infraestrutura urbana, no sentido centro-periferia, assim como são regiões que, em geral, apresentam um maior número de vazios urbanos, que intensificam a segregação socioespacial das populações periféricas (SANTOS, 1990). Tendo em vista esse cenário, este artigo tem como objetivo analisar a qualificação, em termos de uso e forma urbana, dos entornos dos terminais de ônibus urbanos situados nas periferias do Eixo Anhanguera, em Goiânia. Esses equipamentos (Padre Pelágio e Novo Mundo) se situam em importantes zonas intersticiais da capital e abarcam, através da abrangência de suas linhas alimentadoras, uma grande parcela de sua mancha urbana (Figura 1). Pretende-se verificar se os entornos desses terminais conformam centralidades capazes de atender às demandas cotidianas das populações servidas pelas linhas alimentadoras, de modo a atenuar a necessidade de deslocamento para o Centro e impactar positivamente na pegada ecológica dessas comunidades periféricas.

Figura 1 - Eixo Anhanguera e a amplitude de alcance dos seus terminais periféricos

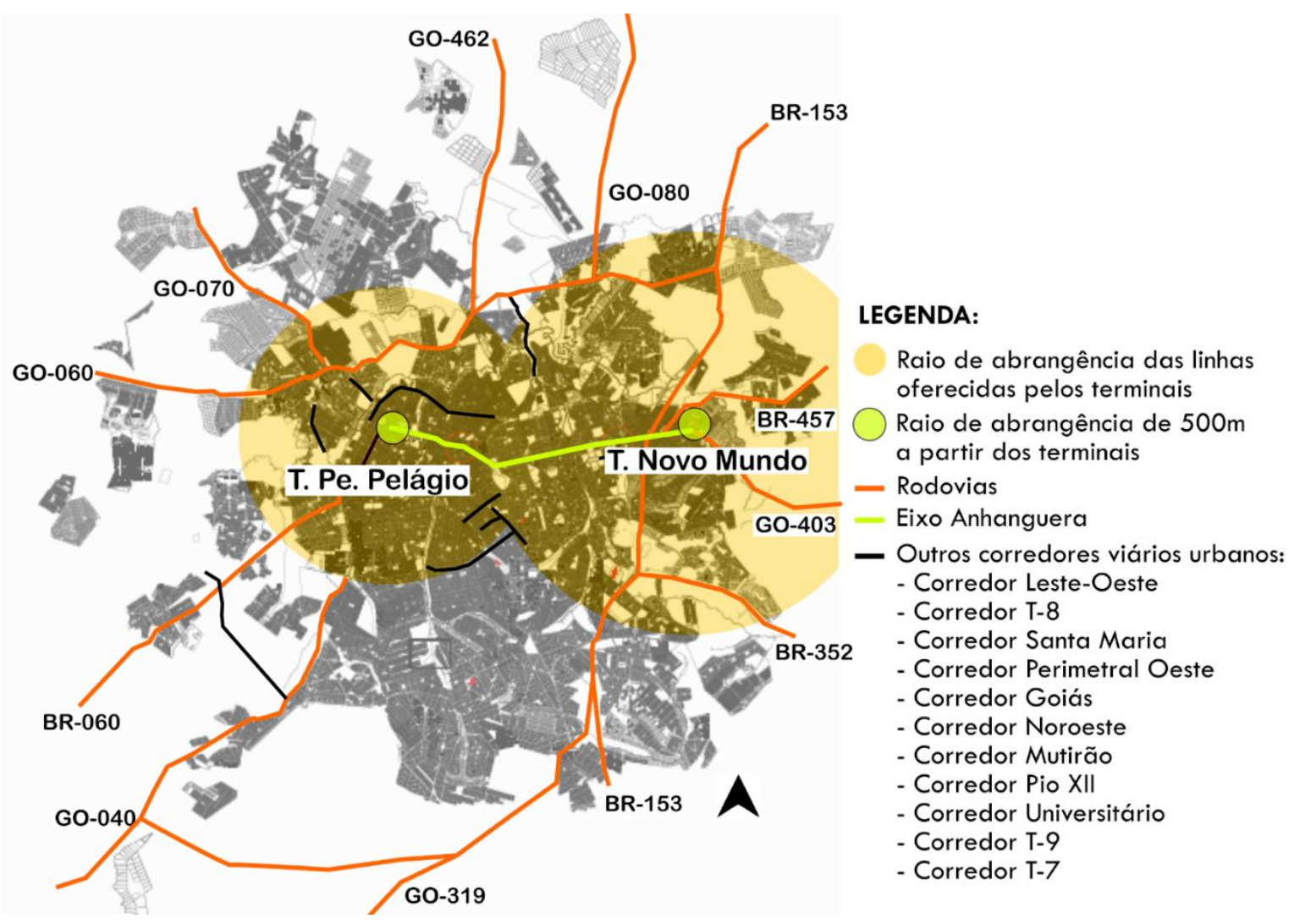

Fonte: Autoras, adaptado de Prefeitura de Goiânia (2014) 


\section{REVISÃO BIBLIOGRÁFICA}

Quando se aborda a necessidade de reduzir deslocamentos e emissões de CO2 na cidade contemporânea, deve-se ter em mente que o objetivo de trabalhar uma forma urbana compacta está associado a deter, o mais próximo possível das origens de deslocamento, os destinos essenciais ao cotidiano da população. Muitas vezes, essas atividades se concentram nas centralidades urbanas. As centralidades conformam polos econômicos, sociais, políticos e, até mesmo, a caracterização como espaços simbólicos relacionados à memória da urbe (BARRETO, 2010).

A expansão desmensurada da mancha urbana e processos mais complexos de saturação, obsolescência e transformação das características socioeconômicas de uma determinada centralidade tradicional formalizam alguns dos fatores motivadores da ascensão de novas centralidades (OLIVEIRA JÚNIOR, 2008). Se concebidas numa perspectiva de planejamento sistêmico, estas podem auxiliar na superação da segregação das populações periféricas (CASTELLS, 2012), também atenuando a pegada ecológica dessas comunidades, ao passo que favorecem oportunidades de emprego e acesso a serviços essenciais próximo de onde se sediam (NEWMAN, 2016, p.147).

É importante desvelar as relações de dependência e atendimento que as populações periféricas detêm para com os serviços e equipamentos dispostos em outras localidades (VIANA, 2010), como também certificar se estas conformam centralidades efetivas. Para Pereira et al. (2011), há variáveis que determinam o que configura as centralidades, como: os fluxos que centralizam, o grau de concentração de habitações e postos de trabalho, a proximidade e a aglomeração de atividades urbanas.

Quanto mais efetiva for uma centralidade, mais ela tem a contribuir na vitalidade de um espaço urbano que, por sua vez, retroalimenta a centralidade, reforçando-a (RAMALHO et al., 2016). A vitalidade de uma área detém estreita relação ao modo como a forma urbana e a paisagem se estruturam em usos, escalas e no grau de permeabilidade das edificações com as vias. A percepção de um espaço vital diz respeito à diversidade de atividades que ocorrem num determinado espaço urbano, às suas dinâmicas e horários de funcionamento (JACOBS, 2009 [1961]), a como as arquiteturas posicionadas ao longo das vias se abrem ao espaço público, a como sua escala dialoga com a escala humana (GEHL, 2013) e a como a estrutura fundiária, no tamanho dos lotes e suas testadas, proporciona um ritmo de atividades e de variação paisagística, contribuindo para um ambiente dinâmico (WATERMAN, 2012), todos os aspectos válidos a um estudo que pretende avaliar se contextos urbanos configuram centralidades.

\section{PROCEDIMENTOS METODOLÓGICOS}

Os terminais urbanos são equipamentos que detêm um potencial de conformação de centralidades em seu entorno próximo por centralizarem fluxos. Os cinco terminais que compõem o Eixo Anhanguera aglutinam 80 linhas do transporte coletivo da capital (GOIÁS, 2019, s/p). Dessas, 24 se destinam ao Terminal Padre Pelágio e 25 atendem ao Terminal Novo Mundo.

Mas, há fatores de ordem espacial e ambiental que corroboram a ascensão de uma centralidade urbana, sendo importante avaliar a performance dessas centralidades na perspectiva do pedestre, a partir do acesso a essas áreas através do terminal. Portanto, delimita-se a análise da forma urbana a um raio de 500m, lançado a partir do terminal. Essa distância é entendida por Gehl (2013) como convidativa à caminhada, ainda que se deva ponderar que o relevo, a dinamização do espaço urbano, a sua 
configuração e a condição individual daqueles que transitam por este, são fatores que relativizam esse buffer.

Nessa delimitação territorial se empreende um estudo de uso do solo, compreendendo a demarcação das atividades comerciais, serviços, equipamentos públicos e instituições. Para avaliar a intensidade e suficiência dessas atividades nos contextos urbanos, aplica-se um indicador de nível de interação de atividades em vias extraído do Sistema de Certificação do Urbanismo Ecossistêmico. Esses indicadores compõem o eixo de "complexidade urbana" da ferramenta, que pode ser entendido como a condição urbana ideal para a mescla e coexistência de usos habitacionais junto a atividades terciárias (MUÑOZ, 2015, p.29).

A complexidade urbana é alcançada através da promoção de corredores contínuos de atividades que transformam a rua num espaço vital (MUÑOZ, 2015). Na Certificação do Urbanismo Ecossistêmico, os corredores são avaliados a partir dos critérios dispostos na Tabela 1.

Tabela 1 - Indicadores para a mensuração do grau de interação de atividades numa via

\begin{tabular}{cc}
\hline Grau de interação na via & Atividades distribuídas ao longo das vias a cada $\mathbf{1 0 0 \mathrm { m } \text { lineares }}$ \\
\hline Interação muito alta & $>10$ atividades $/ 100 \mathrm{~m}$ lineares \\
Interação alta & $=10$ atividades $/ 100 \mathrm{~m}$ lineares \\
Interação suficiente & $5-10$ atividades $/ 100 \mathrm{~m}$ lineares \\
Interação insuficiente & $2-5$ atividades $/ 100 \mathrm{~m}$ lineares \\
Interação muito insuficiente & $<2$ atividades/ $100 \mathrm{~m}$ lineares \\
\hline
\end{tabular}

Fonte: Autoras, adaptado de Alted (2016)

Esses indicadores fornecem balizas para um segundo nível de análise, também desenvolvida através de mapas: as intensidades de interação de atividades nas margens de cada uma das vias do entorno dos terminais. Quanto maior o número de vias que disponham de mais de 10 atividades ocorrendo a cada $100 \mathrm{~m}$ lineares, maior é a frequência e ritmo destas e maior é a probabilidade de se concretizar um meio urbano vital, favorecendo a efetivação de uma centralidade urbana.

\section{RESULTADOS}

O mapa de uso do solo da Figura 3 evidencia a vocação comercial do entorno do Terminal Padre Pelágio, uma vez que esse é o uso que se faz mais presente na análise que já permite antever a presença de grandes vazios urbanos e de poucos equipamentos públicos para além do terminal, sinalizando uma fragilidade à sua constituição como centralidade.

No caso do Terminal do Novo Mundo, o mapa de uso do solo (Figura 2) mostra que seu entorno é composto, em grande parte, pelo uso residencial e que há a conformação de corredores comerciais que não se dão nas margens imediatas da via que comporta o terminal. Contudo, o contexto urbano do Terminal Novo Mundo apresenta uma presença mais expressiva de instituições e um índice menor de vazios urbanos se comparado ao do Terminal Padre Pelágio. 
Figura 2 - Uso do solo no entorno dos terminais Padre Pelágio (à esquerda) e Novo Mundo (à direita)
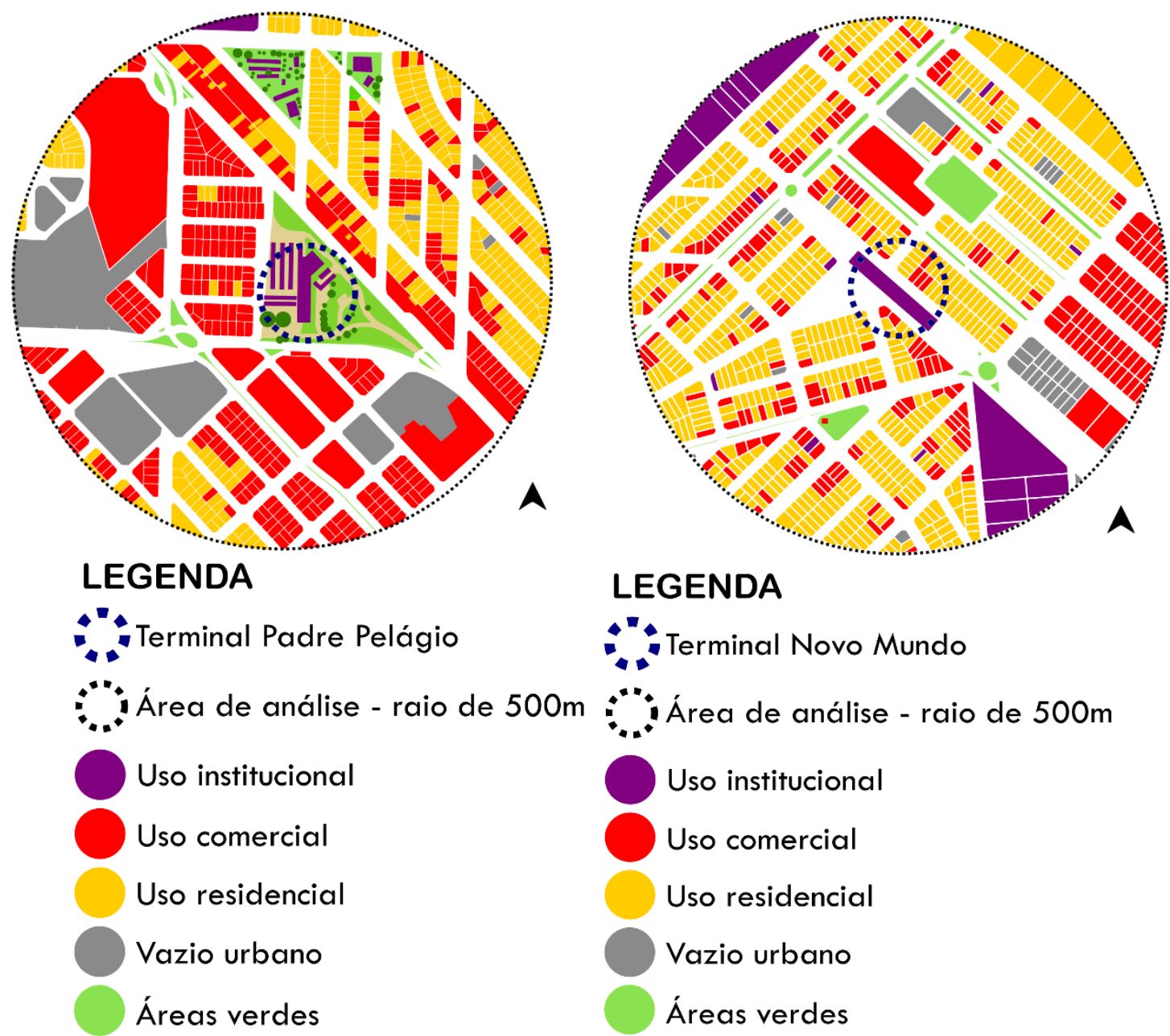

\section{LEGENDA}
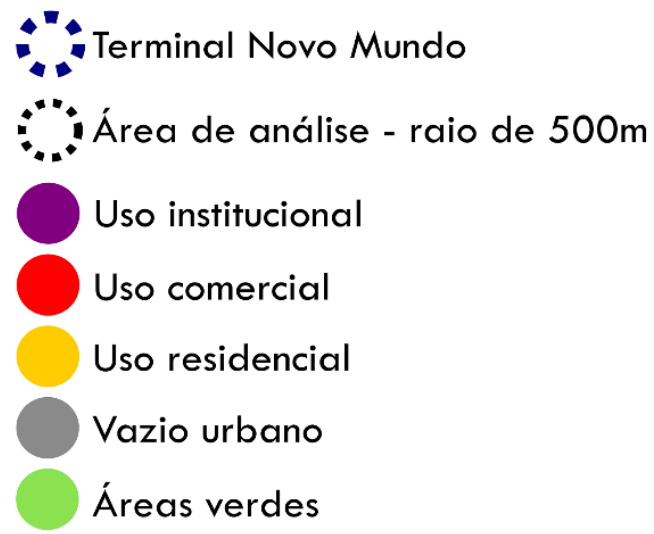

Fonte: Autoras, adaptado de Prefeitura de Goiânia (2014)

Quando se avalia o grau de interação das atividades, a partir dos indicadores da Tabela 1, os resultados extraídos dos mapas da Figura 3 relativizam algumas das primeiras impressões geradas pelos estudos de uso do solo. Se, a princípio, a Figura 2 antevê uma provável centralidade comercial no entorno do Terminal Padre Pelágio, o que se observa nesse contexto urbano, através da Figura 3, é que o grau de interação das atividades é majoritariamente insuficiente. Somente na margem oposta ao terminal, na Avenida Anhanguera, encontra-se um contexto de interação suficiente, alta e, pontualmente, muito alta. No caso do entorno do Terminal Novo Mundo, que, a princípio, parecia ter uma menor vocação comercial, na análise de interação das atividades, mostrou-se mais vital pela incidência comparativamente maior de interações altas e muito altas de atividades tanto no entorno do terminal, como na via caracterizada como corredor comercial, que o intercepta a noroeste. 
Figura 3 - Grau de interação das atividades a cada 100m lineares no entorno dos terminais Padre Pelágio (à esquerda) e Novo Mundo (à direita)
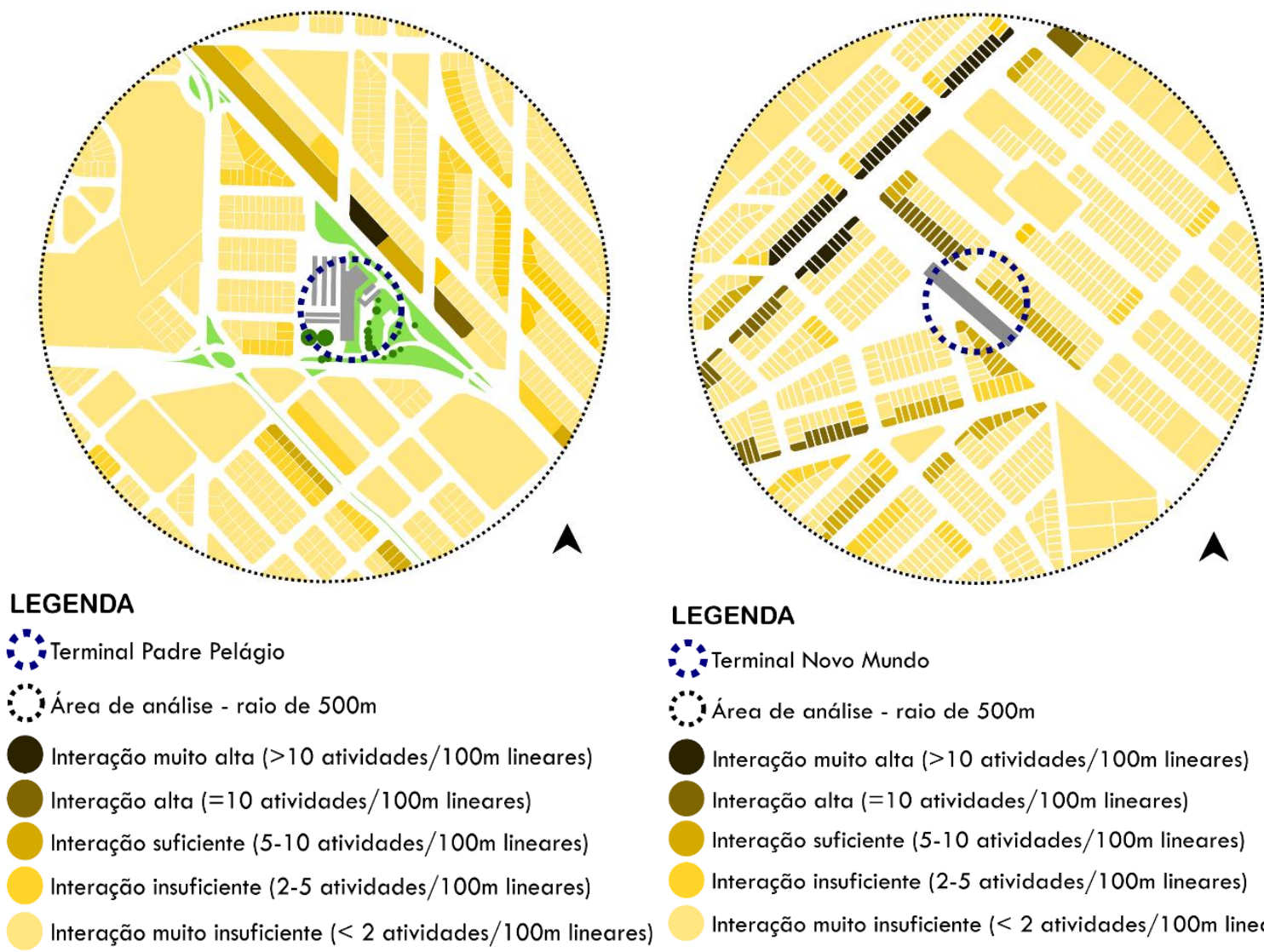

"Terminal Novo Mundo

Área de análise - raio de $500 \mathrm{~m}$

Interação muito alta (>10 atividades $/ 100 \mathrm{~m}$ lineares)

Interação alta ( $=10$ atividades $/ 100 \mathrm{~m}$ lineares)

Interação suficiente (5-10 atividades $/ 100 \mathrm{~m}$ lineares)

Interação insuficiente (2-5 atividades/100m lineares)

Interação muito insuficiente (< 2 atividades $/ 100 \mathrm{~m}$ lineares)

Fonte: Autoras, adaptado de Prefeitura de Goiânia (2014)

A análise mediante os indicadores sistematizados na Tabela 1, permite compreender a escala que as atividades comerciais detêm efetivamente no espaço. Como as zonas de interação qualificadas como suficientes, altas e muito altas são pontuais nos contextos dos dois terminais, o que se pode inferir é que estes não se efetivam como centralidades.

O Terminal Padre Pelágio apresenta uma implantação e escala diferente das do Novo Mundo, como se pode observar nas Figuras 2 e 3. A configuração avantajada e as áreas livres em seus arredores fazem com que o terminal se isole do contexto urbano, o que possivelmente compromete sua vitalidade. A grande escala do equipamento também é acompanhada pela magnitude dos estabelecimentos comerciais do seu entorno, caracterizados por galpões, comércio atacadista e fábricas muradas.

O Terminal Novo Mundo, além da escala mais aproximada à humana e aos padrões de ocupação da área, sedia-se no eixo central da via, algo também comum às estações elevadas de ônibus do Eixo Anhanguera. Essa estratégia de implantação permite a proximidade e a apreensão visual das duas margens da via, possibilitando uma maior comunicação entre essas bordas e favorecendo a ocorrência de atividades comerciais. 


\section{CONCLUSÕES}

Os resultados desta pesquisa demonstram que se os entornos dos terminais periféricos do Eixo Anhanguera não se efetivam como centralidades, é pouco provável que esses equipamentos formalizem um destino final aos usuários do transporte público. Isso representa um impacto na pegada ecológica das comunidades periféricas, já que, para além dos deslocamentos através das linhas alimentadoras, a população ainda é impelida a prolongar seus trajetos até o alcance das centralidades.

Os resultados permitem identificar fragilidades dos territórios que impedem sua ascensão como centralidades. Essas circunstâncias se diferenciam entre os dois contextos. No caso do Terminal Padre Pelágio, o que se impõe é a escala de ocupação do terminal em si e das atividades do seu entorno, além da não consolidação efetiva do território, mediante os vazios urbanos. Já no Terminal Novo Mundo, o principal impeditivo reside na constituição majoritária do contexto urbano através do uso residencial.

Os resultados sinalizam a importância de se conferir estímulo ao uso misto do solo e se reverter padrões de ocupação dissociados da escala humana, inibindo também os vazios urbanos através da própria legislação urbanística. O estudo evidenciou a relevância que o desenho urbano e estratégias de implantação dos equipamentos detêm no desempenho de suas áreas de abrangência, com destaque para a inserção dos terminais em reciprocidade a um projeto de cidade para as pessoas.

Cabe mencionar que para estudos futuros se faz necessário detalhar as categorias de atividades urbanas que se encontram no entorno desses terminais, de modo a verificar se atendem às necessidades cotidianas de seus usuários. Também pode se fazer interessante levantar a movimentação em número de passageiros em cada terminal, sendo esses desdobramentos para esta pesquisa.

\section{REFERÊNCIAS}

ALTED, M. C. Aplicació del model de les Superilles Urbanes a la ciutat de València. Dissertação (Mestrado em Transporte, Território e Urbanismo). València: Universitat Politécnica de València, 2016.

BARRETO, R. O centro e a centralidade urbana: aproximações teóricas a um espaço em mutação. Cadernos do Curso de Doutoramento em Geografia FLUP, Porto, v.1, n.1, p. 23-4, 2010.

CASTELLS, M. Space of flows, space of places: Materials for a theory of urbanism in the information age. In BISHWAPRIYA, S. (org.) Comparative planning cultures. New York: Routledge, 2012, pp.1-12. Disponível em: <https://www.taylorfrancis.com/books/e/9780203826508/chapters/10.4324\%2F9780203826508-10>. Acesso em 01 jan. 2019.

GEHL, J. Cidades para pessoas. São Paulo: Perspectiva, 2013.

GOIÁS, Governo do Estado. História do Eixo Anhanguera. In Metrobus. Goiânia: Governo do Estado de Goiás, 2019. Disponível em: <https://www.metrobus.go.gov.br/eixo-anhanguera/hist\%C3\%B3ria.html>. Acesso em 07 abr. 2021.

JACOBS, J. Morte e vida de grandes cidades. São Paulo: Editora WMF Martins Fontes, 
2009 [1961].

MUÑOZ, V. M. Urbanismo ecossistêmico: caso práctico. Trabalho final de graduação (Graduação em Arquitetura). València: Universitat Politècnica de València, 2015.

NEWMAN, P. Perth as a "big" city: reflections on urban growth. Thesis Eleven, v. 135, n.1. Reino Unido: Sage, p.139-151, 2016.

OLIVEIRA JÚNIOR, G. A. Redefinição da centralidade urbana em cidades médias. Sociedade \& Natureza, Uberlândia, v1, n.20, p.205-220, 2008.

PEREIRA, R. H. M. et al. Quantificando a centralidade urbana: uma proposta de índice simples e comparação internacional. Rio de Janeiro: Instituto de Pesquisa Econômica Aplicada - IPEA, 2011.

RAMALHO, T. C. S. S. et al. Centralidade e vitalidade urbana no centro histórico de cidades de médio porte: uma reflexão acerca da cidade de Pau dos Ferros/RN. In Urbicentros V, 2016, João Pessoa. Anais... João Pessoa: UFPB, 2016, p. 1-14.

SANTOS, M. A metrópole: modernização, involução e segmentação. VALLADARES, L. \& PRETECEILLE, E. (orgs.). Reestruturação Urbana - tendências e desafios. São Paulo: NOBEL/IUPERJ, 1990, pp.183-191.

VIANA, D. L. Cidade Africana - Urbanismo [in]formal: uma abordagem integrada e sistémica. In $7^{0}$ Congresso Ibérico de estudos africanos, 2010, Lisboa. Anais... Lisboa: ISTE - Instituto Universitário de Lisboa, 2010, p.1-15.

WATERMAN, Tim. Desenho Urbano. Porto Alegre: Bookman, 2012. 